\title{
Формирование пленки CaSi2 в условиях радиационного воздействия на структуру $\mathrm{CaF}_{2} / \mathrm{Si}$
}

\author{
А.В. Кацюба ${ }^{1}$, А.В. Двуреченский ${ }^{1,2}$, Г.Н. Камаев ${ }^{1}$, В.А. Володин ${ }^{1,2}$ \\ ${ }^{1}$ ИФП СО РАН, Новосибирск, 630090, пр. Ак. Лаврентьева, 13 \\ ${ }^{2}$ Новосибирский государственный университет, 630090, Новосибирск, ул. Пирогова, 2 \\ тел:+7 (383) 333-2624, эл.nочта: kacyuba@isp.nsc.ru
}

DOI 10.34077/RCSP2021-52

Возросший интерес к пленкам $\mathrm{CaSi}_{2}$ обусловлен возможностью получать высококачественные эпитаксиальные пленки $\mathrm{CaSi}_{2}$ на кремниевых подложках, что позволяет не только формировать элементы проводящих структур, таких как контакты и соединения в компонентах интегральных схем, но и в качестве активных элементов, включая фотоэлектрические и термоэлектрические чувствительные элементы, при создании систем с пониженной размерностью, в технологических процессах безрезистного формирования наноструктур, совместимых с кремниевой технологией. Помимо возможности эпитаксиального роста на $\mathrm{Si}, \mathrm{CaSi}_{2}$ имеет уникальную слоистую кристаллическую структуру, состоящую из гексагонального бислоя $\mathrm{Si}$ и тригонального монослоя Са, что позволяет рассматривать этот материал в качестве прототипа для получения 2D структур на основе Si.

В настоящей работе представлены результаты исследований по изучению возможности формирования тонких пленок $\mathrm{CaSi}_{2}$, путем воздействия электронного пучка с энергией 20 кэВ и


радиационно-стимулированного роста [1]. Эксперименты проводились на установке молекулярнолучевой эпитаксии (МЛЭ) «Катунь-100», оснащенной эффузионным источником $\mathrm{CaF}_{2}$ с графитовым тиглем. После стандартной для МЛЭ предростовой подготовки поверхности подложки Si ориентации (111) на ней выращивался буферный слой $\mathrm{Si}$ толщиной 100 нм, затем осуществлялся эпитаксиальный рост пленки $\mathrm{CaF}_{2}$. Формирование пленки $\mathrm{CaSi}_{2}$ осуществлялось в двух вариантах. В первом случае (формирование пленки $\mathrm{CaSi}_{2}$ непосредственно в процессе эпитаксиального роста $\mathrm{CaF}_{2}$ в условиях воздействия электронного пучка на растущий $\mathrm{CaF}_{2}$ ) в течение всего времени эпитаксиального роста $\mathrm{CaF}_{2}$ проводилось облучение электронами. Во втором варианте (формирование пленки $\mathrm{CaSi}_{2}$ в условиях воздействия электронного пучка на $\mathrm{CaF}_{2}$ при заданной температуре после эпитаксиального роста пленки $\mathrm{CaF}_{2}$ ) после окончания роста поверхность $\mathrm{CaF}_{2}$ подвергалась облучению электронным пучком при заданной температуре.

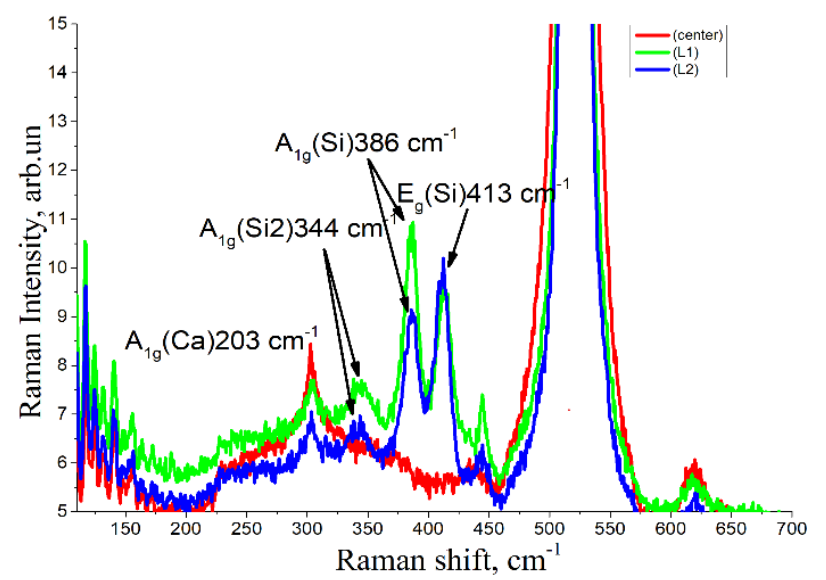

Методом спектроскопии комбинационного рассеяния света (КРС) установлено, что эффект фазового превращения пленки $\mathrm{CaF}_{2}$ в пленку $\mathrm{CaSi}_{2}$. в условиях облучения электронами происходит как в процессе эпитаксии, так и после формирования пленки $\mathrm{CaF}_{2}$ при температурах выше $300{ }^{\circ} \mathrm{C}$. При увеличении толщины пленки $\mathrm{CaF}_{2}$ более 20 нм обнаружен переход фазы $\mathrm{CaSi}_{2}$. пространственной группы $\mathrm{R} 3 \mathrm{~m}$ с 3-х слойным трансляционным периодом кремниевых подструктур в элементарной ячейке (3R) к 6-ти слойному (6R) [2]. На рисунке в качестве примера представлены спектры КРС образца с толщиной пленки $\mathrm{CaF}_{2} 10$ нм, снятые вне зоны облучения (center), в области падения пучка электронов в процессе роста пленки (L1) и в области падения пучка электронов после роста пленки (L2). Сравнивая спектр (center) со спектрами, зарегистрированными от облученной области (кривые L1, L2) видно, что облучение в обоих случаях привело к появлению характерных пиков в области $413 \mathrm{~cm}^{-1}, 386 \mathrm{~cm}^{-1}$ и $344 \mathrm{~cm}^{-1}$. Эти пики свойственны для $\mathrm{CaSi}_{2}$ полиморфа 3R.

Исследование выполнено при финансовой поддержке РФФИ и Госкорпорации «Росатом» проект № 20-21-00028.

\section{Лumepamypa}

[1] A.V.Kacyuba, A.V.Dvurechenskii, G.N.Kamaev, V.A.Volodin, A.Y.Krupin. Materials Letters. 2020. $268 \mathrm{c}$.

[2] A.V.Kacyuba, A.V.Dvurechenskii, G.N.Kamaev, V.A.Volodin, A.Y.Krupin. Journal of Crystal Growth.2021. Vol. 562. 